\title{
Anti-BCMA/PBD ADC MEDI2228
}

National Cancer Institute

\section{Source}

National Cancer Institute. Anti-BCMA/PBD ADC MEDI2228. NCI Thesaurus. Code C150127.

An antibody-drug conjugate (ADC) consisting of a fully human monoclonal antibody against the tumor-associated antigen (TAA) B-cell maturation antigen (BCMA, TNFRSF17) that is site-specifically conjug ated, via a protease-cleavable linker, to a cytotoxic, DNA minor groove crosslinking agent and pyrrolobenzodiazepine (PBD) dimer, with potential antineoplastic activity. Upon administration of anti-BCMA/PBD ADC MEDI2228, the antibody moiety targets the cell surface antigen BCMA expressed on certain cancer cells. Upon antibody/antigen binding, internalization and lysosomemediated cleavage, the cytotoxic PBD moiety is released. In turn, the imine groups of the PBD moiety bind to the N2 positions of guanines on opposite strands of DNA. This induces DNA strand breaks, inhibits DNA replication, leads to G2/M cell cycle arrest, induces cell death, and inhibits the proliferation of BCMA-overexpressing tumor cells. BCMA, a receptor for a proliferation-inducing lig and (APRIL; tumor necrosis factor lig and superfamily member 13; TNFSF13), and B-cell activating factor (BAFF), is a member of the tumor necrosis factor (TNF) receptor superfamily and plays a key role in plasma survival; it is found on the surfaces of plasma cells and is overexpressed on malignant plasma cells. 